\title{
Bond strength of composite resin containing biomaterial S-PRG to eroded dentin
}

\author{
Alessandra Sanchez Coelho Lourenço ${ }^{1}$, Ana Paula \\ Almeida Ayres ${ }^{2}$, Taís Fonseca Mantilla ${ }^{3}$, Marcelo \\ Giannini ${ }^{4}$, Patricia Moreira de Freitas ${ }^{5}$
}

${ }^{1}$ DDS, Department of Restorative Dentistry, School of Dentistry, Universidade de São Paulo (USP), SP, Brazil.

${ }^{2}$ DDS, MSc, PhD, Department of Restorative Dentistry, University of Uberaba, Uberaba, MG, Brazil.

${ }^{3}$ DDS, MSc, Department of Restorative Dentistry, School of Dentistry, Universidade de São Paulo (USP), SP, Brazil.

${ }^{4}$ DDS, MSc, PhD, Department of Dental Materials, Piracicaba Dental School, Faculdade de Odontologia de Piracicaba (UNICAMP),

Piracicaba, SP, Brazil.

${ }^{5}$ DDS, MSc, PhD, Special Laboratory of Lasers in Dentistry, Department of Restorative Dentistry, School of Dentistry, Universidade de São Paulo (USP), SP, Brazil.

Corresponding author:

Patricia Moreira de Freitas

Laboratório Especial de Laser em Odontologia (LELO)

Faculdade de Odontologia -

Universidade de São Paulo

Av. Professor Lineu Prestes, 2226 -

Cidade Universitária, Butantã, São

Paulo, Brazil

+55 11 3091-7645

pfreitas@usp.br

Received: May 31, 2017

Accepted: September 14, 2017

Aim: To evaluate the bond strength of composite resin containing or not biomaterial (S-PRG) to sound/eroded dentine. Methods: Occlusal dentin of 30 human molars $(n=15)$ had half of its surface kept uneroded, while on the other half an erosive lesion was produced by cycling in citric acid ( $\mathrm{pH}$ 2.3) and supersaturated solution ( $\mathrm{pH}$ 7.0). On both eroded (ED) and non-eroded (SD) substrates, two restorative systems (containing or not S-PRG) were tested. Composite resin cylinders were built and, after storage in water (24h), were submitted to bond strength test. The analysis of the fracture pattern was performed under an optical microscope (40x). The obtained values of bond strength $(\mathrm{MPa})$ were submitted to ANOVA (two factors) and Tukey multiple comparisons tests $(p<0.05)$. Results: According to the results, there was difference between substrates $(<0.001)$ and restorative materials $(p=0.002)$ evaluated. For the microtensile bond strength, the values obtained were: SDNB $(47.6 \pm 12.2 \mathrm{MPa})$, SDWB (34.1 $\pm 15.8 \mathrm{MPa})$, EDNB $(31.1 \pm 8.3 \mathrm{MPa})$ and EDWB $(15.5 \pm 13.6 \mathrm{MPa})$, revealing a statistically significant difference in the evaluated substrates and restorative materials. Conclusion: Bond strength of eroded substrate is inferior to the sound substrate and the restorative system containing S-PRG biomaterial influences negatively the results of bonding to sound/eroded dentin.

Keywords: Biomaterial S-PRG. Erosion. Union resistance. 


\section{Introduction}

Dental erosion is a chemical process characterized by the dissolution of hard dental tissues resulting from exposure to a variety of acids of non-bacterial origin'. Intrinsic factors such as gastroesophageal reflux and regurgitations resulting from eating disorders (anorexia and/or bulimia) are associated with this pathology, as well as extrinsic factors, which are more common nowadays due to acidic diets resulting from healthy foods or conditions related to profession ${ }^{2,3}$. The factors that generate tooth erosion may be of multiple origins and its diagnosis should be followed by measures to control its progression or even to restore the function and aesthetics of the compromised teeth ${ }^{4}$ In this context, direct restorative techniques are indicated on the affected surfaces, being performed on the enamel or, in more advanced cases (severe lesions), on dentin 4 .

Although in the last decade the technological evolution has been huge with respect to adhesive restorative materials, it is still a great challenge to achieve an equally effective adhesion in different dental tissues, with dentin being the most critical substrate for adhesion 5 .

Among the adhesive systems available in the market and of interest in the context of the control of the dental substrate demineralization process, fluoride adhesive systems, which can release fluoride ions ${ }^{6}$, are distinguished from other restorative materials by their capability to penetrate into the dentin and provide a more effective source of fluoride ${ }^{7,8}$. However, it is not known if the fluoride concentration released would be able to offer some benefit to the dentin, either for the inhibition of demineralization or the activation of dentin remineralization. Also, the actual role of fluoride release in restorative materials in erosion prevention is not yet fully understood ${ }^{9}$.

A composite resin containing the S-PRG particle (Surface Pre-Reacted Glass/Pre-Activated Surface Ionomer, patented and exclusive technology GIOMER-SHOFU Inc., Kyoto, Japan) was developed with properties much like that of a glass ionomer cement in many aspects and at the same time with physical properties of a composite. The advantage of the material seems to be the release of six different ions (fluoride, sodium, strontium, aluminum, silicate and borate), known to have bioactive properties ${ }^{10}$. The S-PRG filler particles are formed by an acid-base reaction between fluoroaluminosilicate glass and polyacrylic acid ${ }^{1}$ and are capable of fluoride releasing and recharging. Therefore, the material is able to provide significant effects on remineralization throughout cariogenic challenges, inhibiting carbohydrate metabolism in the biofilm, promoting acid neutralization in the oral cavity, and being able to control the demineralization process of the dental substrate ${ }^{10-12}$.

Up to the moment, the literature reports studies on the adhesion of this material only to sound or demineralized (secondary caries lesions) dental surfaces ${ }^{13}$. Considering that fluoride containing products can be of great interest for the restoration of erosive lesions, controlling future tooth mineral loss, this in vitro study evaluated the bond strength of composite resin restorations, containing or not S-PRG biomaterial, to the sound and eroded dentin surfaces. The working hypotheses tested in this study were: (A) there were no differences in bonding effectiveness to eroded and non-eroded dentin surfaces irrespective of which restorative system was applied and (B) a restorative 
system with S-PRG particles in the composition would not influence the bond strength to dentin (eroded or not) when compared to the a conventional restorative system.

\section{Materials and Methods}

\section{Ethical Aspects}

This study protocol was approved by the Committee of Ethics on Research of the School of Dentistry of the University of Sao Paulo (Protocol n. 1.730.958).

\section{Study Design}

The sample units of the present study consisted on 60 human dentin discs, obtained from 30 human third molar teeth. The factors under study were the substrate type in 02 levels (sound dentin/SD and eroded dentine/ED) and restorative systems in 02 levels (containing/WB or not/NB the biomaterial S-PRG). Samples were randomly divided in 4 groups $(n=15)$ : SDNB (sound dentin/no biomaterial in the restorative system), SDWB (sound dentin/ with biomaterial in the restorative system), EDNB (eroded dentin/ no biomaterial in the restorative system) and EDWB (eroded dentin/ with biomaterial in the restorative system). The response variable obtained was the microtensile bond strength (MPa) between the sound/eroded dentin surfaces and the restorative system. The evaluations were performed after $24 \mathrm{~h}$ storage in deionized water. The analysis of the fracture pattern was also performed in a descriptive way. Fluxogram of samples' distribution is shown in Figure 1.

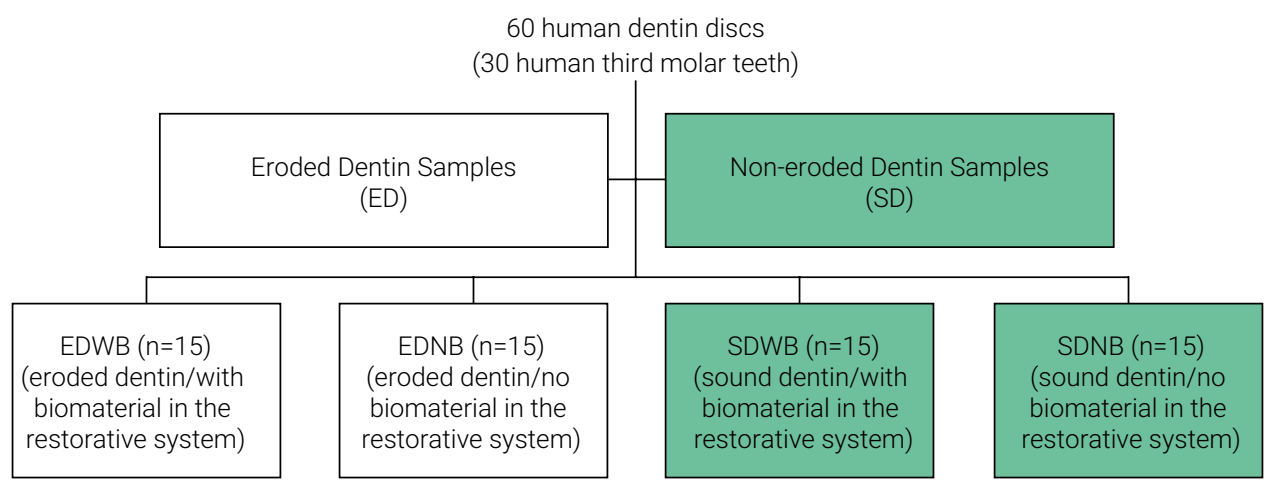

Figure 1. Fluxogram of samples' distribution.

\section{Sample Preparation}

Thirty recently extracted third molars were collected from the Human Teeth Bank of the School of Dentistry of the University of São Paulo. The teeth were stored in $0.5 \%$ chloramine $T$ solution under refrigeration $\left(4^{\circ} \mathrm{C}\right)$ for a maximum period of three months after the extraction date. The teeth were cleaned using periodontal curettes (Duflex, SS White, Rio de Janeiro, RJ, Brazil) and polishing with pumice (SS White, Rio de Janeiro, RJ, Brazil) and water with the aid of Robinson's brush (KG Sorensen, Barueri, SP, Brasil), followed by washing with distilled water. 
After cleaning, the teeth were fixed with sticky wax (Asfer Indústria Química Ltda, São Paulo, Brazil) on a metal plate (Gibraltar's Jig), with the dentin-enamel junction perpendicular to the plate. Initially, the teeth had the occlusal enamel removed with a double-sided diamond disc (Buehler, UK Ltd, Lake Bluff, IL, USA), in a metallographic slicer for exposing the dentin surface at low speed (100 rpm), coupled to a cutting machine (Isomet 1000, Buehler Ltd, Lake Buff, IL, USA) and under water cooling. Then, the specimens were polished and planned manually in a low speed (100 rpm) polishing machine (Ecomet 3 - Buehler Ltd, Lake Buff, IL, USA) using silicon carbide discs (Buehler Ltd, Lake Buff, IL, USA) of decreasing granulations $\# 120$, \#240, \#400, under constant irrigation. Between the use of each polishing sandpaper disc, the specimens were ultrasonically washed with deionized water for 5 minutes.

All specimens were included in polyvinyl chloride (PVC) tubes containing acrylic resin (JET Clássico, São Paulo, SP, Brazil) to enable specimen fixation. After inclusion, the specimens were polished with \#600 granulation sandpaper to standardize the smear layer. The dentin occlusal surface (dentin hemi-disc) was protected with adhesive tape, except in a delimited area that corresponded to the sound surface. The artificially eroded dentin was produced on the exposed dentin surface.

\section{Erosive cycling}

The demineralization was done by immersing the specimens in $10 \mathrm{ml}$ of $0.05 \mathrm{M}$ citric acid solution (E. Merck, D-6100 Darmstadt, F.R., Germany), pH 2.3, 6 immersions of 10 minutes each, during 5 days ${ }^{14}$. Between each immersion in acidic solution, with an interval of 1 hour each, and during the remaining time (other periods of the day in which the samples were not immersed in the acid solution), the specimens were stored in $10 \mathrm{ml}$ of remineralizing solution, consisting of $\mathrm{H}_{3} \mathrm{PO}_{4} 4.08 \mathrm{mM}, 20.10 \mathrm{mM} \mathrm{KCl}, 11.90 \mathrm{mM}$ $\mathrm{Na}_{2} \mathrm{CO}_{3^{\prime}}$ and $1.98 \mathrm{mM} \mathrm{CaCl}_{2}, \mathrm{pH}$ 6.7, under gentle stirring (30 rpm) (Polymax 1040, Incubator 1000, Heidolph Instruments $\mathrm{GmbH} \&$ Co. KG, Schwabach, Germany). After each immersion, the samples were carefully washed with distilled water for 1 minute and gently dried with absorbent paper and then placed in the container of the next solution. The solutions were renewed at the beginning of each day of the experiment and the $\mathrm{pH}$ value of all the solutions was controlled at the beginning and at the end of each experimental day. After the last erosive cycling, the samples were immersed for 24 hours in supersaturated solution and then stored in a humid environment with distilled-deionized water until the surface treatments and adhesive procedures were performed.

\section{Surface Treatments}

After obtaining the hard and artificially eroded dentin hemidiscs, 15 samples were treated with the restorative system not containg the S-PRG particles and 15 samples with the restorative system containg the S-PRG particles, both used according to the manufacturer's instructions (Table 1).

After the application of the adhesive systems, composite resin blocks (A3 color) were built on the dentin surfaces that were previously delimited with a pen to differentiate between sound and eroded dentin. Each 2-mm-thick increment was photoactivated for 20 seconds using an LED light curing device (RADII - SDI, Victória, AU) with a power density of approximately $1,200 \mathrm{~mW} / \mathrm{cm}^{2}$. The intensity of the light-curing source was monitored by means of a radiometer (Curing Light Meter 105, Demetron Research Corporation, USA). 
Table 1. Description of the adhesive materials used in the present study (information given by manufacturers).

\begin{tabular}{|c|c|c|}
\hline Material (Manufacturer) & Composition (\# Bath) & Application's Mode \\
\hline $\begin{array}{l}\text { Adper Single Bond } 2 \text { (3M } \\
\text { ESPE, St. Paul, USA), } \\
\text { pH } 4.7\end{array}$ & $\begin{array}{l}\text { Acid Conditioner: } 35 \% \text { phosphoric acid } \\
\text { - pH = } 0.6 \\
\text { Adhesive: Bis-GMA, HEMA, } \\
\text { dimethacrylates, photoinitiator, } \\
\text { functional methacrylate, polyacrylic } \\
\text { acid copolymer and polyacrylic acid, } \\
10 \% \text { by weight of } 5 \text { nm diameter } \\
\text { spheroidal silica particles, water, } \\
\text { ethanol (1703000272) }\end{array}$ & $\begin{array}{l}\text { Acid Conditioning - apply for } 15 \mathrm{~s} \text {, } \\
\text { wash for } 15 \mathrm{~s} \\
\text { Application of the adhesive for } 20 \mathrm{~s} \text {. } \\
\text { Gently dry (air jet) for } 5 \mathrm{~s} \text {. } \\
\text { Photopolymerization for } 10 \mathrm{~s} \text {. }\end{array}$ \\
\hline $\begin{array}{l}\text { Filtek Z350 XT (3M ESPE, } \\
\text { St. Paul, USA) }\end{array}$ & $\begin{array}{l}\text { Bis-GMA, BisEMA, UDMA, TEGDMA, } \\
\text { combination of silica and zirconia } \\
\text { aggregates }(5-20 \mathrm{~nm}) \text {, and } \\
\text { nanoparticles of silica }(20 \mathrm{~nm}) / 78.5 \% \\
\text { by weight ( } 1636100289)\end{array}$ & $\begin{array}{l}\text { Application of increment with a } \\
\text { maximum of } 2 \mathrm{~mm} \text { of thickness. } \\
\text { Photopolymerization for } 20 \mathrm{~s} \text {. }\end{array}$ \\
\hline $\begin{array}{l}\text { FL-Bond II Adesive } \\
\text { System (Shofu Inc., } \\
\text { Kyoto, Japan) pH } 2.2\end{array}$ & $\begin{array}{l}\text { Primer: Ethanol, methacrylate adhesive } \\
\text { monomer } \\
\text { Bonding Resin: HEMA, UDMA, TEGDMA } \\
\text { and SPRG Glass particles (041501) }\end{array}$ & $\begin{array}{l}\text { Passive application of the primer } \\
\text { on the surface, leaving it for } 10 \mathrm{~s} \text {. } \\
\text { Gently dry (air jet) for } 5 \mathrm{sec} \text {. Apply the } \\
\text { adhesive over the entire surface. } \\
\text { Photopolymerization for } 10 \mathrm{~s} \text {. }\end{array}$ \\
\hline $\begin{array}{l}\text { Beautifil II/Shofu Inc., } \\
\text { Kyoto, Japan }\end{array}$ & $\begin{array}{l}\text { Bis-GMA, TEGDMA, multi-functional } \\
\text { glass particles, S-PRG particles (based } \\
\text { on fluoroboroaluminosilicate) (081470) }\end{array}$ & $\begin{array}{l}\text { Application of increment with a } \\
\text { maximum of } 2 \text { mm of thickness. } \\
\text { Photopolymerization for } 20 \mathrm{~s} \text {. }\end{array}$ \\
\hline
\end{tabular}

\section{Microtensile bond strength test}

After the adhesive procedures and the composite resin blocks were obtained, the samples were stored in distilled-deionized water $\left(37^{\circ} \mathrm{C}\right)$ in a greenhouse for a period of 24 hours and then sectioned to obtain sticks ${ }^{15}$.

The samples were fixed in wax (Asfer Indústria Química Ltda, São Paulo, Brazil) on a metal plate (Isomet 1000, Buehler Ltd., Lake Bluff, Illinois, USA), the most perpendicular to the double-sided diamond disk (Buehler Ltd Lake Bluff, IL, USA). Each sample was sectioned in the buccal-lingual direction and in the mesio-distal direction perpendicular to the dentin-composite union interface, with a rotation of $100 \mathrm{rpm}$, under water cooling, obtaining stick-shaped specimens with dimensions of approximately $1.0 \times 1.0 \mathrm{~mm}$. Sticks obtained from the margins of the resin block were discarded. After being examined in a stereoscopic magnifying glass (Olympus, Tokyo, Japan) in a 30x magnification with the objective to exclude those with defects in the adhesive interface, bubbles, cracks or remnants of enamel, approximately 2 to 6 sticks per sample were selected and stored for another 24 hours to be submitted to the microtensile bond strength test.

The device containing the stick sample was coupled to the universal test machine (Instron 5942, Canton, MA, USA), and loaded with $50 \mathrm{~N}$ (speed of $0.5 \mathrm{~mm} / \mathrm{min}$ ) until fracture of the sample. Microtensile bond strength was recorded in Newton ( $N$ ) and values were calculated and expressed in $\mathrm{MPa}$, using the formula: bond strength $(\mathrm{MPa})=$ strength $(\mathrm{N}) /$ sample cross-sectional area $\left(\mathrm{mm}^{2}\right)$. 


\section{Failure Mode}

After the microtensile bond strength test was performed, all specimens were mounted on glass slides and the fractured surfaces were analyzed under a stereoscopic magnifier (Olympus SZ60, Olympus Corporation, Tokyo, Japan), with a magnification of 60x. The failure mode was classified as follows: type I-adhesive; type II-cohesive in dentin; type III-cohesive in composite resin; type IV-mixed.

\section{Data analysis}

Each tooth was considered a sample unit, so all sticks of a single tooth gave a mean value of bond strength. The data were submitted to statistical analysis by means of ANOVA (two factors, repeated-measures) and Tukey's multiple comparisons tests, using the statistical software SigmaPlot (Systat Software, Inc), version 12.5, considering the level of significance of $5 \%$.

\section{Results}

\section{Microtensile bond strength test}

The obtained values of microtensile bond strength (MPa) were submitted to ANOVA (two factors, repeated-measures) and Tukey's multiple comparisons tests $(p<0.05)$ and consisted on: SDNB (47.6 $\pm 12.2 \mathrm{MPa})$, SDWB $(34.1 \pm 15.8 \mathrm{MPa})$, EDNB $(31.1 \pm 8.3 \mathrm{MPa})$ and EDWB $(15.5 \pm 13.6 \mathrm{MPa})$. According to the results, there was no statistically significant difference on the interaction between substrate and restorative materials (0.711). However, as shown in table 2, there was difference between the substrates and the restorative materials evaluated.

Table 2. Microtensile bond strength (MPa) values and standard deviation of each experimental group.

\begin{tabular}{lccc}
\hline & & Restorative System & \\
\hline Substrate & 3M/ESPE (PC) & Shofu (SE) & p value \\
\hline Sound Dentin (SD) & SDPC & SDSE & 0.008 \\
\hline Eroded Dentin(ED) & $47.6 \pm 12.2$ & $34.13 \pm 15.80$ & \multirow{2}{*}{0.003} \\
\hline$p$ value & EDPC & EDSE & \\
\hline
\end{tabular}

\section{Failure Mode}

In groups SDNB and SDWB (sound dentin), the predominant fracture mode for both adhesive systems was adhesive failure, corresponding to $65.9 \%$ in SDNB and $88.67 \%$ in SDWB. The percentages of mixed failure were $27.7 \%$ for SDNB and $13.2 \%$ for SDWB, followed by cohesive failure in dentin of $6.87 \%$ in the SDNB group and $3.77 \%$ in the SDWB group (Fig. 2).

In dentin submitted to erosive cycling, the EDNB obtained $70.88 \%$ of adhesive fractures, $26.58 \%$ of mixed fracture and $8.86 \%$ of cohesive fractures in resin, and in EDWB there were $100 \%$ of adhesive failures (Fig. 2). 


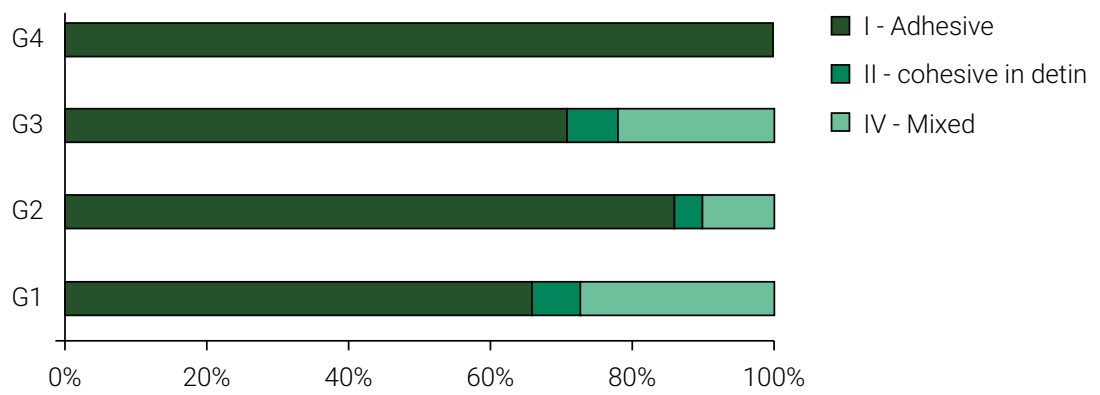

Figure 2. Percentage of failure mode for each experimental group.

\section{Discussion}

Compared to sound dentin, eroded dentin was consistently related to lower microtensile bond strength, irrespective of the adhesive system. Therefore, the two hypotheses might be rejected, since eroded dentin did not present the same bonding effectiveness than non-eroded dentin and the restorative system containing biomaterial S-PRG had a negative influence on dentin bond strength.

Different modifications on the surface of restorative materials and dental surfaces have been reported after an erosive challenge. Erosion jeopardizes properties as morphology ${ }^{16}$, surface roughness ${ }^{17}$, hardness ${ }^{18}$ and wear depth ${ }^{19}$. The reduction of dentin bond strength is widely reported ${ }^{20,21}$ and it is probably a consequence of the combination of these deleterious effects. Only one study reported that eroded dentin does not jeopardize the immediate microtensile bond strength of the adhesive restorative materials evaluated ${ }^{22}$. This result might be related to the different $\mathrm{pH}$ cycling mode, products and test utilized in the contradictory study.

Eroded dentin exhibit structural alteration of inorganic content ${ }^{23,24}$ causing unprotected collagen exposure ${ }^{24}$. The acidic nature of erosion agents might also activate metalloproteinases, contributing to enzymatic degradation of the substrate over time ${ }^{25}$. These differences between sound and eroded dentin might have interfered with the bonding properties of the restoration materials evaluated, irrespective to the presence of the biomaterial S-PRG. Apparently, the collagen fibrils' disorganization of the softened and demineralized dentin is not modified by acid etching pretreatment and impairs monomers infiltration, thus hindering the formation of an adequate hybrid layer ${ }^{26}$. Other possible explanation is that the altered morphological structure of the eroded dentin presents more porosities that jeopardize the evaporation of hydrophilic components, resulting on inferior bond strength ${ }^{26}$.

In dental literature, etch-and-rinse bonding systems tend to provide higher bond strength than self-etching ones ${ }^{27}$. Ultra-morphologically, there is a marked difference between the hybrid layers of these adhesive techniques bonded to dentin ${ }^{28}$. The adhesive system FL Bond II is considered "mild" regarding the acidity as it has a relatively high $\mathrm{pH}$, around 2.2. This category of self-etching adhesives promotes incomplete smear layer dissolution and/or incorporation, while the phosphoric acid used in etchand-rinse adhesives removes the smear debris and demineralize the surface of the dentin ${ }^{29}$. After the rinsing phase, the adhesive is applied to dentin and resin monomers 
infiltrate into the dentinal tubules and into the collagen fibrils network, forming long resin tags and a thick hybrid layer, respectively. Conversely, a very thin hybrid layer and short resin tags are formed with mild-acidity self-etching adhesive systems applied to dentin ${ }^{29}$. The intense micromechanical interlocking produced by phosphoric acid etching might explain the higher bond strength observed to the Adper Single Bond 2. Contradictory results ${ }^{30}$ found better results for self-etch approach when compared to etch-and-rinse bond strength results, which infers that the bonding effectiveness to eroded dentin might be product-dependent. Forgerini et al. ${ }^{21}$ (2017) reported that the use of an universal adhesive did not provide the same bonding efficacy on eroded dentin as on sound dentin, irrespective of the etching mode.

In all groups the most frequent failure mode was adhesive. It infers a good reliability of the present $\mu$ TBS test conditions and correlates well with the literature for eroded dentin bonded to adhesive systems ${ }^{20,30-32}$. On the other hand, eroded dentin restored with ionomer based materials usually shows higher incidence of cohesive and mixed failure $^{22}$. This fact might be related to the intrinsic cohesive material properties and also associated to the very common presence of air bubbles in glass ionomer cements that can act as stress points, increasing the likelihood of cohesive fracture within the cement ${ }^{33}$. In the present study, the eroded dentin restored with the self-etch adhesive presented $100 \%$ of adhesive failure, which is compatible with the worst bond strength result and indicates that the weakest zone is concentrated in the hybrid layer.

Although preventive effects of different fluoride formulations on erosive tooth wear ${ }^{34}$ and on dentin mechanical properties ${ }^{35}$ have shown positive results, our findings suggest that the fluoride-releasing restorative material used in this study showed no evidence of bond strength improvement to eroded dentin. According to the respective manufacturer, the S-PRG particles of FL-Bond II adhesive system establish chemical bonding to the inorganic content of the dentin and releases fluoride. Since the erosion demineralizes superficial dentin, less hydroxyapatites are available to interact with the ions present in the S-PRG molecules, which might partially explain the lower bond strength found to this adhesive system. Bollu et al. (2016) reported high microleakage for giomer and speculate that it was caused by polymerization shrinkage stress of this material ${ }^{36}$, while some authors suggest that the main cause the for the margin deterioration observed might be the intrinsic hygroscopic expansion of this restorative materia| ${ }^{37}$.

Other possible explanation for the lower performance of FL-Bond II is that due to its mild acidity, the adhesive components may not penetrate the whole depth of the demineralized layer produced by erosion, resulting in incomplete resin infiltration. The hypothesis that a prolonged primer application time would results in better penetration was tested by Deari et al. ${ }^{32}$, applying OptiBond FL Prime (Kerr, Scafati, Italy) for a prolonged duration (60 s instead of $15 \mathrm{~s}$ ). However, this technique did not improve the bond strength of eroded dentin.

Despite the lower immediate bond strength results using composite resin containing biomaterial S-PRG, further studies should be conducted to investigate the influence of the chemical interaction between S-PRG and inorganic content of eroded dentin in long-term storage evaluation. 
In conclusion, eroded dentin compromises the bonding quality of adhesive systems. The adhesive system not containing the biomaterial showed higher bond strength values to non-eroded and eroded dentin than the S-PRG based restorative system.

\section{References}

1. Lussi A, Schlueter N, Rakhmatullina E, Ganss C. Dental Erosion - An overview with emphasis on chemical and histopathological aspects. Caries Res. 2011;45 Suppl 1:2-12.

2. Zero DT. Etiology of dental erosion - extrinsic factors. Eur J Oral Sei. 1996 Apr; 104(2):162- 77.

3. Salas MM, Nascimento GG, Vargas-Ferreira F, Tarquinio SB, Huysmans MC, Demarco FF. Diet influenced tooth erosion prevalence in children and adolescents: Results of a meta-analysis and meta-regression. J Dent. 2015 Aug;43(8):865-75.

4. Carvalho TS, Colon P, Ganss C, Huysmans MC, Lussi A, Schlueter N, et al. Consensus report of the European Federation of Conservative Dentistry: erosive tooth wear-diagnosis and management. Clin Oral Investig. 2015 Sep;19(7):1557-61.

5. Van Meerbeek B, Yoshihara K, Yoshida Y, Mine A, De Munck J, et al. State of the art of self-etch adhesives. Dent Mater. 2011 Jan;27(1):17-28.

6. McCabe JF, Carrick TE, Kamohara H. Adhesive bond strength and compliance for denture soft lining materials. Biomaterials. 2002 Mar;23(5):1347-52.

7. Featherstone JDB, O’Relly MM,Shariati M, Brugler S. Enhacement of remineralization in vitro and in vivo. In: Leach SA. Factors affecting de- and remineralization of the teeth. Oxford: IRL Press; 1986. p. 23-34.

8. Han L, Edward C, Okamoto A, Iwaku M. A comparative study of fluoridereleasing adhesive resin materials. Dent Mat J. 2002; 21(1): 9-19.

9. Soares LE, Lima LR, Vieira Lde S, Do Espírito Santo AM, Martin AA. Erosion effects on chemical composition and morphology of dental materials and root dentin. Microsc Res Tech. 2012 Jun;75(6):703-10.

10. Gordan VV, Mondragon E, Watson RE, Garvan C, Mjor IA. A clinical evaluation of a self-etching primer and a giomer restorative material: results at eight years. J Am Dent Assoc. 2007;138(5):621-7.

11. Moretto SG, Azambuja N Jr, Arana-Chavez VE, Reis AF, Giannini M, Eduardo Cde P,et al.. Effects of ultramorphological changes on adhesion to lased dentin-Scanning electron microscopy and transmission electron microscopy analysis. Microsc Res Tech. 2011 Aug;74(8):720-6.

12. Shiozawa M, Takahashi H, Iwasaki N. Fluoride release and mechanical properties after 1-year water storage of recent restorative glass ionomer cements. Clin Oral Investig. 2014 May;18(4):1053-60.

13. Ayres APA, Tabchoury CP, Bittencourt Berger S, Yamauti M, Bovi Ambrosano GM, Giannini M. Effect of Fluoride-containing Restorative Materials on Dentin Adhesion and Demineralization of Hard Tissues Adjacent to Restorations. J Adhes Dent. 2015 Aug;17(4):337-45.

14. Ganss C, Klimek J, Schãffer U, Spall T. Effectiveness of two fluoridation measures on erosion progression in human enamel and dentin in vitro. Caries Res. 2001 SepOct;35(5):325-30.

15. Sano H, Shono T, Sonoda H, Takatsu T, Ciucchi B, Carvalho R, et al. Relationship between surface area for adhesion and tensile bond strength-eval uation of a micro-tensile bond test. Dent Mater. $1994 \mathrm{Jul} ; 10(4): 236-40$.

16. Honório HM, Rios D, Francisconi LF, MagalhÃes AC, MacHado MAAM, Buzalaf MAR. Effect of prolonged erosive pH cycling on different restorative materials. J Oral Rehabil. 2008;35(12):947-53. 
17. Badra VV, Faraoni JJ, Ramos RP, Palma-Dibb RG. Influence of different beverages on the microhardness and surface roughness of resin composites. Oper Dent. 2005;30(2):213-9.

18. Wongkhantee S, Patanapiradej V, Maneenut C, Tantbirojn D. Effect of acidic food and drinks on surface hardness of enamel, dentine, and tooth-coloured filling materials. J Dent. 2006 Mar;34(3):214-20.

19. Pedroso C, Anderson AT, Hara T, Jorge S, Mo DAE. Study on the potential inhibition of root dentine wear adjacent to fluoride-containing restorations. J Mater Sci Mater Med. 2008 Jan;19(1):47-51.

20. Amsler F, Lussi A. Long-Term Bond Strength of Self-Etch Adhesives to Normal and Artificially Eroded Dentin : Effect of Relative. 2017;19(2):169-77.

21. Forgerini TVRocha R de Oliveira, Soares FZM, Lenzi TL RJF. Role of Etching Mode on Bonding Longevity of a Universal Adhesive to Eroded Dentin. J Adhes Dent. 2017;19(1):69-76.

22. Cruz JB, Lenzi TL, Tedesco TK, Guglielmi C de AB, Raggio DP. Eroded dentin does not jeopardize the bond strength of adhesive restorative materials. Braz Oral Res. 2012;26(4):306-12.

23. Wang X, Lussi A. Assessment and management of dental erosion. Dent Clin North Am. 2010;54(3):565-78.

24. Prati C, Montebugnoli L, Suppa P, Valdrè G, Mongiorgi R. Permeability and Morphology of Dentin after Erosion Induced by Acidic Drinks. J Periodontol. 2003;74(4):428-36.

25. Buzalaf MAR, Kato MT, Hannas AR. The Role of Matrix Metalloproteinases in Dental Erosion. Adv Dent Res. 2012;24(2):72-6.

26. Wang $Y$, Spencer P. Effect of acid etching time and technique on interfacial characteristics of the adhesive-dentin bond using differential staining. Eur J Oral Sci. 2004;112(3):293-9.

27. Masarwa N, Mohamed A, Abou-Rabii I, Abu Zaghlan R, Steier L. Longevity of Self-etch Dentin Bonding Adhesives Compared to Etch-and-rinse Dentin Bonding Adhesives: A Systematic Review. J Evid Based Dent Pract. 2016 Jun;16(2):96-106.

28. Giannini M, Makishi P, Ayres APA, Vermelho PM, Fronza BM, Nikaido T, et al. Self-etch adhesive systems : a literature review. Braz Dent J. 2015 Jan-Feb;26(1):3-10.

29. Wang Y, Spencer P. Quantifying adhesive penetration in adhesive/dentin interface using confocal Raman microspectroscopy. J Biomed Mater Res. 2002;59(1):46-55.

30. Ramos TM, Ramos-Oliveira TM, de Freitas PM, Azambuja N, Esteves-Oliveira M, Gutknecht N, et al. Effects of Er:YAG and Er,Cr:YSGG laser irradiation on the adhesion to eroded dentin. Lasers Med Sci. 2015;30(1):17-26.

31. Frattes FC. Bond strength to eroded enamel and dentin using a. Universal Adhesive System. J Adhes Dent. 2017;19(2):121-7.

32. Deari S, Wegehaupt J, Tauböck TT. Influence of different pretreatments on the microtensile bond strength to eroded dentin. J Ades Dent. 2017;19(2):147-55.

33. Burrow M., Nopnakeepong U, Phrukkanon S. A comparison of microtensile bond strengths of several dentin bonding systems to primary and permanent dentin. Dent Mater. 2002;18(3):239-45.

34. Lussi A, Carvalho TS. The future of fluorides and other protective agents in erosion prevention. Caries Res. 2015;49(suppl 1):18-29.

35. Paula A, Guedes A, Moda MD, Umeda TY, Gustavo A, Godas DL, et al. Effect of Fluoride-Releasing Adhesive Systems on the Mechanical Properties of Eroded Dentin. Braz Dent J. 2016 Mar-Apr;27(2):153-9.

36. Bollu IP, Hari A, Thumu J, Velagula LD, Bolla N, Varri S, et al. Comparative evaluation of microleakage between nano-ionomer, giomer and resin modified glass ionomer cement in class $\vee$ cavities- CLSM study. J Clin Diagnostic Res. 2016;10(5):ZC66-ZC70.

37. Sunico MC, Shinkai K, Katoh Y. Two-year clinical performance of occlusal and cervical giomer restorations. Oper Dent. 2005;30(3):282-9. 